\title{
Analysis of SAGE II ozone of the middle and upper stratosphere for its response to a decadal-scale forcing
}

\author{
E. Remsberg ${ }^{1}$ and G. Lingenfelser ${ }^{2}$ \\ ${ }^{1}$ NASA Langley Research Center, 21 Langley Blvd., Mail Stop 401B, Hampton, VA 23681, USA \\ ${ }^{2}$ SSAI, 1 Enterprise Parkway, Hampton, VA 23661, USA
}

Received: 10 June 2010 - Published in Atmos. Chem. Phys. Discuss.: 16 July 2010

Revised: 6 December 2010 - Accepted: 7 December 2010 - Published: 10 December 2010

\begin{abstract}
Stratospheric Aerosol and Gas Experiment (SAGE II) Version 6.2 ozone profiles are analyzed for their decadal-scale responses in the middle and upper stratosphere from September 1991 to August 2005. The profile data are averaged within twelve, $20^{\circ}$-wide latitude bins from $55^{\circ} \mathrm{S}$ to $55^{\circ} \mathrm{N}$ and at twelve altitudes from 27.5 to $55.0 \mathrm{~km}$. The separate, 14-yr data time series are analyzed using multiple linear regression (MLR) models that include seasonal, 28 and 21month, 11-yr sinusoid, and linear trend terms. Proxies are not used for the 28-mo (QBO-like), 11-yr solar uv-flux, or reactive chlorine terms. Instead, the present analysis focuses on the periodic 11-yr terms to see whether they are in-phase with that of a direct, uv-flux forcing or are dominated by some other decadal-scale influence. It is shown that they are inphase over most of the latitude/altitude domain and that they have max minus min variations between $25^{\circ} \mathrm{S}$ and $25^{\circ} \mathrm{N}$ that peak near $4 \%$ between 30 and $40 \mathrm{~km}$. Model simulations of the direct effects of uv-flux forcings agree with this finding. The shape of the 11-yr ozone response profile from SAGE II also agrees with that diagnosed for the stratosphere over the same time period from the HALOE data. Ozone in the middle stratosphere of the northern subtropics is perturbed during 1991-1992 following the eruption of Pinatubo, and there are pronounced decadal-scale variations in the ozone of the upper stratosphere for the northern middle latitudes presumably due to dynamical forcings. The 11-yr ozone responses of the Southern Hemisphere appear to be free of those extra influences. The associated linear trend terms from the SAGE II analyses are slightly negative ( -2 to $-4 \% /$ decade) between 35 and $45 \mathrm{~km}$ and nearly constant across latitude. This finding is consistent with the fact that ozone is estimated to have decreased by no more than $1.5 \%$ due to the increasing chlorine from mid-1992 to about 2000 but with little change
\end{abstract}

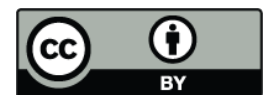

Correspondence to: E. Remsberg (ellis.e.remsberg@nasa.gov) thereafter. It is concluded that a satellite, solar occultation measurement provides both the signal sensitivity and the vertical resolution to record the stratospheric ozone response to the forcing from the solar uv-flux, as well as those due to any other long-term changes.

\section{Background and objectives}

Chemistry-climate models of stratospheric ozone must be able to represent properly both the responses to the uv-flux variations of the solar cycle (SC), as well as those from any long-term changes in the chemical gas families that affect ozone. It is therefore important to analyze observed ozone time series for those same effects, in order to diagnose the performance of the models. Presently, there is some disagreement between analyses of the responses of ozone profiles to the $\mathrm{SC}$ based on satellite data between $25^{\circ} \mathrm{S}$ to $25^{\circ} \mathrm{N}$ versus the responses from representative models (see Fig. 3.19 of WMO (2007)). In particular, the analyses from both the long-term Solar Backscatter Ultraviolet (SBUV) and Stratospheric Aerosol and Gas Experiment (SAGE) ozone data sets indicate a minimum ozone response between about 25 to $35 \mathrm{~km}$ and maximum responses near $25 \mathrm{~km}$ and at $40 \mathrm{~km}$ and above (Soukharev and Hood, 2006; Lee and Smith, 2003). Most models indicate a maximum response to the solar uv-flux from 30 to $40 \mathrm{~km}$ (SPARC CCMVal, 2010). However, there can also be decadal-scale periodicities in the stratosphere at low latitudes that mimic that of the solar cycle forcing, due to dynamical interactions with the quasi-biennial oscillation (QBO) forcing (e.g., Lee and Smith, 2003). Smith and Matthes (2008) report that the diagnosis of such interrelated responses can be problematic based on satellite ozone data that extend for only one or two decades.

Fioletov (2009) reported that photochemical models are in accord with the observed response of SBUV ozone profiles

Published by Copernicus Publications on behalf of the European Geosciences Union. 
to 27-dy, solar cycle variations. He then used that finding to estimate the ozone response to an 11-yr (or SC) forcing. $\mathrm{He}$ found good agreement between the SC response profiles from SBUV and from the models, at least above $35 \mathrm{~km}$. Below $35 \mathrm{~km}$ his estimated, 11-yr response from SBUV was dampened, perhaps because of interannual, dynamical forcings that do not affect the 27-dy response. Soukharev and Hood (2006) also found similar SBUV/model disagreements based on their analyses of a merged ozone dataset (or MOD) from a succession of SBUV instruments. But, Fioletov (2009) pointed out that a part of their disagreement may be traceable to residual biases for the adjusted ozone values from the successive SBUV instruments and that another part may be a result of the relatively low sensitivity and vertical resolution of the SBUV measurement and the retrieval algorithm for its ozone profiles.

The limb, solar absorption (or occultation) technique provides good sensitivity to the variations of the ozone profile and with very good vertical resolution. The occultation method relies on an exo-atmospheric, calibration measurement of the Sun for each of its sunrise and sunset profiles. Solar occultation measurements are necessarily limited in their sampling frequency within a zone of latitude. Even so, their sampling is adequate for resolving the seasonal and longerterm variations in stratospheric ozone across most latitudes. Remsberg (2008) analyzed 14-yr (1991-2005) time series of ozone-versus-pressure profiles from the Halogen Occultation Experiment (HALOE) instrument of the UARS satellite. He obtained an 11-yr response profile with a relative maximum at 4 to $5 \mathrm{hPa}$ (near $37 \mathrm{~km}$ ), which is in reasonable agreement with the modeled SC response profiles of WMO (2007). Of equal importance, Gordley et al. (2009) checked on the performance of the HALOE instrument over its mission life. They found no changes that might have affected the ozone time series of HALOE and their analyzed, 11-yr responses.

The SC-like ozone response profile from the representative model of Brasseur (1993) agrees with that of Remsberg (2008) for HALOE, as shown in Fig. 1. The response profile from the SAGE I plus SAGE II satellite datasets (McCormick et al., 1989) is also shown in Fig. 1 (asterisks), as adopted from Fig. 3.19b of WMO (2007) for the time span of 19792005. An outstanding puzzle is the disagreement for the SClike response profiles from HALOE and the model versus that from the SAGE data (Randel and Wu, 2007; Soukharev and Hood, 2006; WMO, 2007). Those differences are of concern because SAGE ozone measurements have good vertical resolution and ought to be responsive to the natural and anthropogenic forcings. The SAGE II measurements, at least, are believed to have been stable over time, and they are also the benchmark for the determination of long-term trends in stratospheric ozone (Yang et al., 2006).

The primary objective of the present study is to analyze the SAGE II ozone data of the middle and upper stratosphere to see whether they show a significant, 11-yr variation that is in-phase with a direct solar uv-forcing. Only the data from

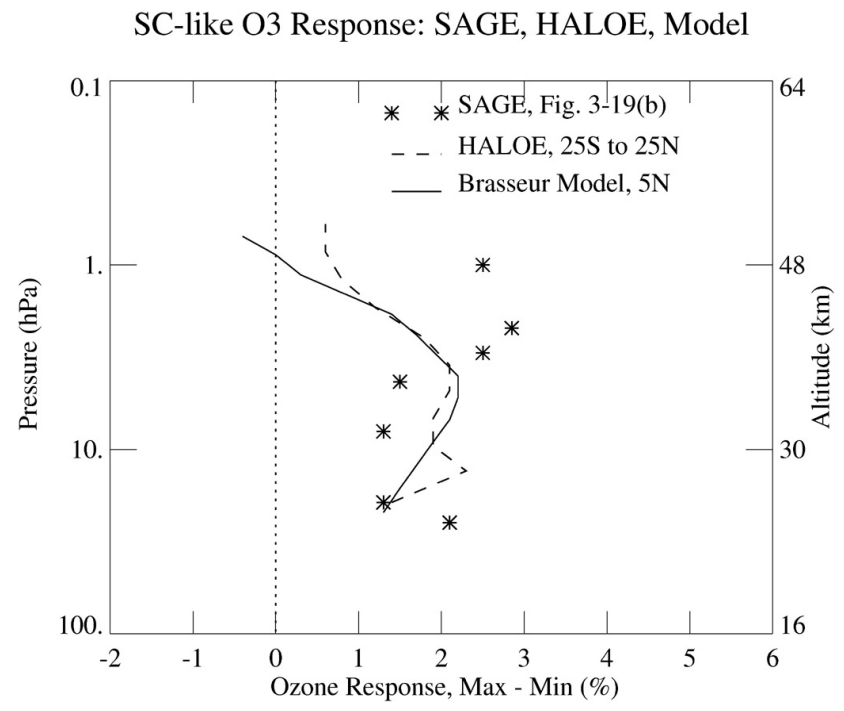

Fig. 1. Solar cycle (or SC-like) ozone response profiles for $25^{\circ} \mathrm{S}$ to $25^{\circ} \mathrm{N}$ from HALOE, from the published analyses of 1979-2005 SAGE data (WMO, 2007, their Fig. 3.19b), and at $5^{\circ} \mathrm{N}$ from the model of Brasseur (1993).

1991 to 2005 are considered here, in order to minimize the effects of the changing chlorine and of those from volcanic aerosols. Essentially, we consider the same approach and time period that was used in the HALOE analyses by Remsberg (2008). There are several reasons for limiting the analysis to just the data from SAGE II and to its more recent time span. First, there is no need to make an adjustment for the lack of overlap between the SAGE I (1979-1981) and the SAGE II (1984-2005) datasets. One can also avoid any bias effects from the volcanic aerosols of El Chichon (1982) that may have affected that adjustment. Further, the effect of the proxy chlorine time series used by Randel and Wu (2007) can be neglected to first order because that term of their regression model was needed mainly to account for the rather large loss of upper stratospheric ozone through the 1980s and the early 1990s. In a check of that approximation Remsberg (2008) estimated the non-linear effect of the changing chlorine from WMO (2007, Figs. 1-12) on the HALOE ozone of 1991-2005 in his Fig. 10. He showed that an Equivalent Effective Stratospheric Chlorine ((EESC) proxy can explain an HALOE ozone decrease in the upper stratosphere of nearly $1.5 \%$ from mid-1992 to 2002, and that his $11-\mathrm{yr}$, max minus min ozone responses may be too large by up to $0.7 \%$ because of not considering an explicit EESC proxy term. Instead, his approach for the HALOE data was to include the effects of the chlorine as part of a linear trend term. It is estimated that his linear approximation imparted a bias of not more than about 0.2 to $0.3 \%$ in his 11 -yr max minus min values. A similar circumstance applies to the use of a linear term for the analysis of the SAGE II data (see Sect. 3). We also conduct separate analyses of the SAGE II data starting 
from September 1992 rather than from mid 1991, in order to assess the perturbing effects from the aerosol layer of the Pinatubo eruption.

A secondary objective is to compare and contrast the 11$\mathrm{yr}$ and the linear trend responses in the ozone data from the solar occultation experiments, SAGE II and HALOE. In several respects the SAGE II ozone distributions ought to be of better quality than those of HALOE for analyses of the 11yr SC response. For example, SAGE II provides a vertical resolution for ozone of order $1 \mathrm{~km}$, obtaining good profile information throughout the stratosphere or at least down to the upper edge of the Pinatubo aerosol layer. SAGE II also provides better seasonal sampling for the middle latitudes than HALOE, which was limited by the power restrictions of the UARS spacecraft near the dates of its yaw maneuvers. In addition, the primary SAGE II data product is in terms of ozone number density $\left(\mathrm{cm}^{-3}\right)$ versus altitude. According to Rosenfield et al. (2005), the linear ozone trends ought to more negative from SAGE II than from HALOE in the upper stratosphere because of the contracting effect of the cooling stratosphere that causes lower number densities to move downward. The periodic, 11-yr term for SAGE II may also have slightly larger amplitude than that from the HALOE ozone of Fig. 1 because the SAGE II results are reported at constant altitudes. Still, differences for this periodic ozone response in the two coordinate systems can be difficult to characterize because the effects of the solar cycle are interactive between ozone and temperature. For example, Frame and Gray (2010) report max minus min, 11-yr temperature versus pressure (or $T(p)$ ) responses from observations of up to $\pm 1 \mathrm{~K}$ for the middle and upper stratosphere. Periodic temperature responses at a constant altitude (or $\mathrm{T}(\mathrm{z})$ ) are a bit larger than for $\mathrm{T}(\mathrm{p})$, as the equivalent pressure levels rise and then fall with time. In the tropics the observed $T(p)$ responses to the solar uv-flux are essentially in-phase, and a positive temperature response at solar maximum translates to a positive response in the atmospheric (and ozone) number density at constant altitude. Although the 11-yr response for $\mathrm{O}_{3}(p)$ is essentially in-phase at all latitudes, the associated 11-yr $\mathrm{T}(\mathrm{p})$ responses become out-of-phase at the middle and high latitudes (Remsberg, 2008). This result at middle latitudes is primarily because of the inverse relationship for ozone and temperature due to the fact that the chemical rate of ozone destruction (or loss of ozone) increases with temperature (e.g., $\mathrm{Li}$ et al., 2002). That inverse relationship also counteracts much of the increase in the atmospheric (and ozone) number density from the temperature response to the uv-flux near the tropical stratopause, as we will show in Section 3. There are also some small, systematic biases and a discontinuity in 2001 in the $T(p)$ time series from the NOAA operational satellite measurements that were used for the registration of the HALOE ozone transmission versus pressure profiles (Shine et al., 2008; Remsberg and Deaver, 2005, their Fig. 4). Such biases affected both the trends and the decadal-scale responses of the HALOE-retrieved ozone in the middle strato- sphere. Therefore, a conversion of the HALOE ozone mixing ratio versus pressure profiles to ozone number density versus altitude is not recommended for a more direct comparison with SAGE II.

Analysis results for 14-yr time series of the SAGE II ozone are presented for altitude levels from 27.5 to $55 \mathrm{~km}$ at intervals of $2.5 \mathrm{~km}$ and for 20-degree wide latitude zones from $55^{\circ} \mathrm{S}$ to $55^{\circ} \mathrm{N}$. Multiple linear regression (MLR) analysis techniques are applied to those time series for their seasonal, interannual, and 11-yr periodic terms and their linear trend terms. The amplitudes of the 11-yr terms are reported versus latitude and altitude; those terms will be shown to be closely in-phase with SC uv-flux proxies. Model estimates of the SC forcing agree reasonably with the SAGE II 11-yr response profiles derived herein at low and middle latitudes, particularly for the Southern Hemisphere. It will also be shown that the models agree better with the SAGE II responses in the subtropics of the Northern Hemisphere after making an allowance for the perturbing effects of the Pinatubo eruption on the ozone of 1991/92. In Section 2 the SAGE II ozone data and the MLR analyses of their time series are described briefly. Examples are provided for several of the SAGE II ozone time series and of the MLR regression model for each of them. Section 3 contains the findings about the 11-yr (or decadal-scale) terms from the MLR model, based on the period September 1991 to August 2005 and then followed by analysis results for the period beginning in September 1992. Section 3 also shows the associated distributions of the trend terms for the SAGE II ozone, providing an important check about the assumed small, linear change in upper stratospheric ozone due to reactive chlorine for this time period. Section 4 compares the trends and the 11-yr response profiles from SAGE II with those from HALOE and from the model. Section 5 is a summary of the findings.

\section{SAGE II ozone data and analysis approach}

The primary ozone product from SAGE II is its number density versus altitude profiles (McCormick et al., 1989; SPARC, 1998). Profiles from the SAGE II version 6.2 algorithms were obtained from (http://www-sage2.larc.nasa. gov/Version6-2Data.html) and used for the analyses herein. Besides the significant interfering effects from the stratospheric aerosols, the only uncertainty for the SAGE II retrieved ozone is from the removal of the Rayleigh extinction component of the measured, ozone channel transmission near $600 \mathrm{~nm}$. However, the Rayleigh extinction becomes comparable to the ozone absorption only near $55 \mathrm{~km}$ and above. The retrieved ozone profiles were screened for several anomalies, as reported in Hassler et al. (2008). In particular, entire ozone profiles were excluded for the period 23 June 1993 to 11 April 1994, whenever their quoted errors exceeded $10 \%$ between $30 \mathrm{~km}$ and $55 \mathrm{~km}$. Note that a more conservative, upper altitude limit of $55 \mathrm{~km}$ was used 
rather than the level of $50 \mathrm{~km}$, recommended by Hassler et al. (2008). Another 67 sunrise (SR) and 2 sunset (SS) profiles were removed; in most cases their ozone densities were negative in the lowermost mesosphere.

Separate SR and SS bin-averaged profiles were then obtained for each of twelve, $20^{\circ}$-wide latitude bins, centered at $55^{\circ} \mathrm{S}$ and extending to $55^{\circ} \mathrm{N}$ in increments of every $10^{\circ}$ of latitude and providing an overlap of $10^{\circ}$ with its adjacent bins. Such averages were obtained at 12 separate altitudes, beginning at $55.0 \mathrm{~km}$ and extending downward to $27.5 \mathrm{~km}$ at intervals of $2.5 \mathrm{~km}$. A minimum of 5 scans was required in order to accept them as being representative for a bin-averaged SR or SS crossing of a latitude zone; in most instances many more profiles were included for each binaveraged point. The SR or SS measurements were obtained as SAGE II progressed across a latitude zone in its orbital viewing opportunities of the Sun. Due to the nature of the sampling of occultation measurements from a moderatelyinclined satellite orbit, each bin-averaged point was obtained from profile observations taken within just a few consecutive days at the low and middle latitudes but over nearly a week at higher latitudes. A screening was not performed to remove the slight biases in the high-altitude SR profile segments that occurred when the SAGE II measurements were taken for brief times (a few successive days) at a high beta angle (Wang et al., 1996). Instead, separate time series of SR and SS values at each altitude and latitude were combined as in Remsberg (2008) to account for any mean SR/SS bias. Each combined time series contains over 200 SR plus SS points. Time spacing between points is somewhat variable but averages from 20 to 25 days, depending on latitude and season.

Figure 2 is an example time series for $25^{\circ} \mathrm{S}$ and at $37.5 \mathrm{~km}$, where the bin-averaged ozone number density values have been multiplied by $10^{-11}$ for ease of display. The data time series points begin in September 1991 and extend through August 2005. Due to a failure of the azimuth gimbal in its pointing system, the SAGE II measurements were taken alternately in a SS and then a SR mode at intervals of about 35 days beginning in mid 2000. Even so, that reduced sampling frequency is adequate for resolving the seasonal and longerterm variations in the ozone within a given $20^{\circ}$-wide latitude bin. MLR analysis models were applied to each of the separate, 144 time series of this study in the manner of Sect. 2.2 of Remsberg (2008). Annual oscillation (AO), semi-annual oscillation (SAO), 853-day or quasi-biennial oscillation (28mo or QBO-like), 640-day or sub-biennial (21-mo or IA), and 11-yr (or SC-like) periodic terms, plus constant and linear trend terms were fit to the data; their combined result for the points of Fig. 2 is shown as the oscillatory curve. The nearly horizontal line is the combination of the constant and linear trend terms. The effects of serial correlation at lag1 were accounted for according to the two-step approach of Tiao et al. (1990), which is analogous to that of the CochraneOrcutt estimator.

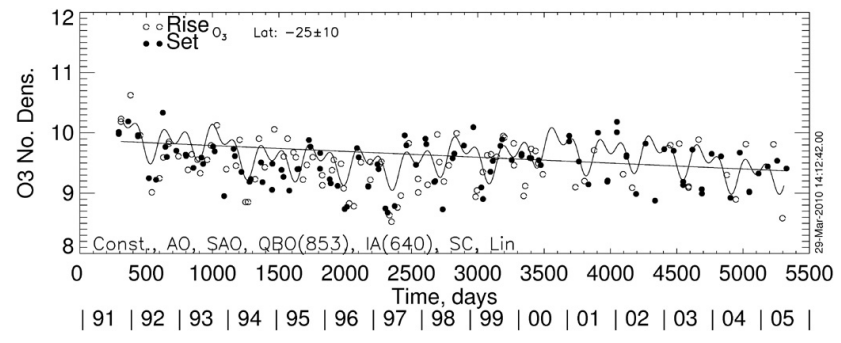

Fig. 2. Time series of bin-averaged, SAGE sunrise and sunset ozone number density measurements (in $\mathrm{cm}^{-3}$ multiplied by $10^{-11}$ ) at $25^{\circ} \mathrm{S}$ and $37.5 \mathrm{~km}$. Terms of the MLR model are indicated at the lower left, where SC refers to an 11-yr sinusoid term. The oscillating solid curve is the model fit to the data, while the straight line curve is the sum of just the constant and linear trend terms.

The MLR model curve in Fig. 2 shows that there is an interaction between the $\mathrm{AO}$ and $\mathrm{SAO}$ terms for this latitude and altitude. There is also an 11-yr term that is in-phase with the solar flux maxima of 1991 and 2002. Contrary to most regression analyses, proxy terms are not used here for the QBO, subbiennial (IA), and 11-yr (or SC-like) model terms. Fourier analyses were applied to the residuals of the preliminary, de-seasonalized time series. Significant, 28-mo and 21-mo interannual terms were found, particularly at the low latitudes. The physical basis of the 21-mo subbiennial term is due to the interaction of the annual and the QBO (28-mo) cycles, as pointed out by Dunkerton (2001). Both of these interannual terms are included in the MLR model. A periodic 11 -yr term is also included, and its phase is checked to see whether it agrees with that of a solar uv-flux proxy. If it is inphase, its max minus min profile is interpreted as primarily due to the direct uv-flux forcing. All the foregoing terms are periodic and therefore orthogonal, such that one can calculate their uncertainties. The present MLR model also does not account separately for the effects of a weak, non-linear trend in reactive chlorine for 1991-2005. That effect is included in a linear trend term, as in the approach of the HALOE analyses of Remsberg (2008). The adequacy of that approximation will be judged in Section 3 by how closely the diagnosed 11 -yr terms are in-phase with a solar uv-flux proxy. As mentioned earlier, there should also be a small, linear decreasing trend due to the cool-to-space effects of the increasing greenhouse gases because the SAGE II ozone is analyzed at constant altitudes. The effects of the Pinatubo aerosols are not considered, except by performing a separate analysis beginning with September 1992 and then comparing its result with that obtained by starting from September 1991 (see Sect. 3.2). Finally, the MLR model residual is checked for any remaining significant structure or anomalies before accepting the model as final.

Figure 3 is the time series plot for $5^{\circ} \mathrm{N}$ and $35 \mathrm{~km}$, and one can clearly see the dominance of the SAO variations in the data. There are also significant contributions from the 


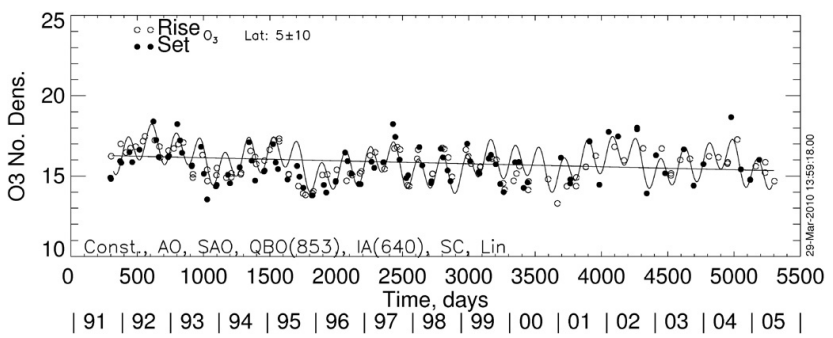

Fig. 3. As in Fig. 2, but for $5^{\circ} \mathrm{N}$ and $35 \mathrm{~km}$.

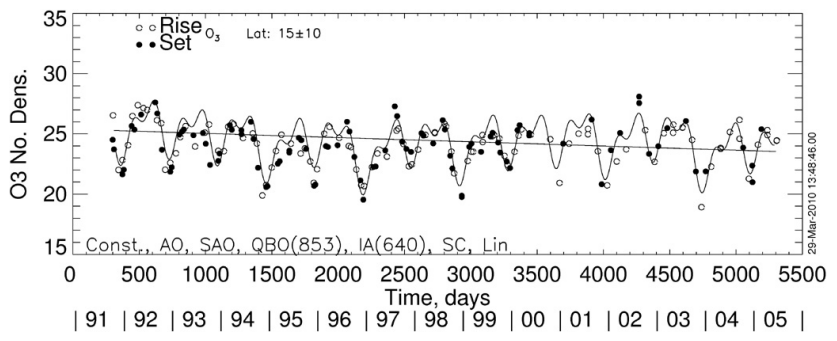

Fig. 4. As in Fig. 2, but for $15^{\circ} \mathrm{N}$ and $32.5 \mathrm{~km}$.

two interannual (QBO and IA) terms. The Fourier analysis of the de-seasonalized residuals for this location from a preliminary run also revealed a weak biennial (or 24-mo) term or a multiple of the AO and SAO terms. More generally, weak-amplitude biennial terms are resolved at 30 to $35 \mathrm{~km}$ throughout the subtropics of the Northern Hemisphere, but not of the Southern Hemisphere. Separate biennial terms are not included in our final MLR models, however.

Figure 4 is an example time series for $32.5 \mathrm{~km}$ and $15^{\circ} \mathrm{N}$. The seasonal and interannual terms of the MLR model have significant amplitudes, and the variations of the ozone with time are a result of their mutual interaction. There is also a significant 11-yr response at this level that is closely in-phase with the solar flux maxima (1991/1992 and 2002/2003). However, in Sect. 3 it will be postulated that a small part of the 11-yr response maximum of 1991/1992 may well be due to the radiative and/or chemical effects for the ozone near the upper boundary of the Pinatubo aerosol layer, followed by a slow ascent of that perturbed ozone to this altitude $(32.5 \mathrm{~km})$. Decadal-scale responses can also arise at this level and latitude, due to interactions of the annual cycle and the QBO (Lee and Smith, 2003; Smith and Matthes, 2008).

A final example time series is shown in Fig. 5 for $27.5 \mathrm{~km}$ and $25^{\circ} \mathrm{N}$ or just above the top of the Pinatubo aerosol layer of 1991/1992. The data are fit very well by the MLR model terms. Generally, the SAGE II ozone time series of this study do not exhibit any evidence for the effects of residual aerosol extinction after about December 1991, even in the northern subtropics and at this low altitude of $27.5 \mathrm{~km}$. The annual (AO) term of the MLR model underestimates the observed ozone densities of late 1991 and early 1992 in Fig. 5, but not

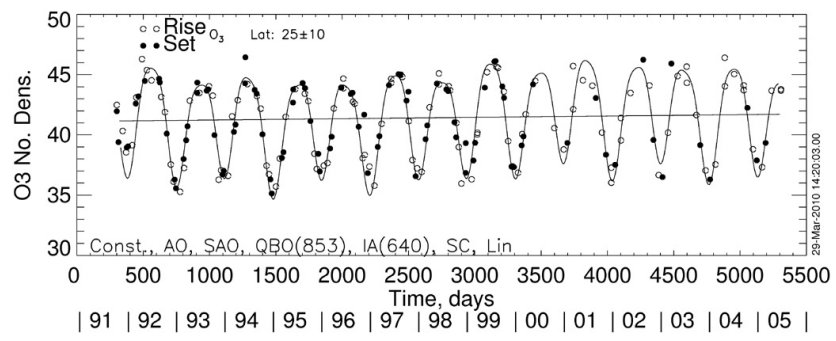

Fig. 5. As in Fig. 2, but for $25^{\circ} \mathrm{N}$ and $27.5 \mathrm{~km}$.

by much and not thereafter. This finding is a testament to the value of the high vertical resolution of the SAGE II aerosol and ozone measurements.

\section{Decadal-scale ozone responses and trend analyses}

\subsection{September 1991 through August 2005}

At the outset it is stressed that the findings presented in this section are viewed as complementary to the ones from the HALOE time series of Remsberg (2008). Instead of regressing against a solar proxy, the approach is to fit an 11-year sinusoidal term to the SAGE II ozone time series. Note that the phase of the 11-yr term is determined simply from its best fit to the data. That term is then checked to see whether its amplitude maximum is essentially in-phase with that of a solar flux proxy. It is recognized that the solar flux variations do not follow an exact, 11-yr sinusoid and that their peak magnitudes vary somewhat from one cycle to the next. A potential complication is that the effects of a direct uv-flux forcing on the ozone can be confounded with any underlying, long-term trend or with a decadal-scale, dynamical forcing of comparable amplitude but perhaps a differing phase. It is argued that one can make a judgment about that prospect by examining the distribution of the phases of the 11-yr terms of the MLR models.

With the foregoing caveat in mind, the distribution of the analyzed, 11-yr responses is shown in Fig. 6 for the SAGE II data of 1991 to 2005. Contours of the max minus min variations (in \%) are determined as twice the coefficient of the 11-yr term divided by the constant term and multiplied by 100 . Note that Fig. 6 is based on separate time series analyses at each of the 144 locations of the altitude/latitude grid. At the Equator the greatest variation is 4 to $5 \%$ at about $35 \mathrm{~km}$. Minimum equatorial values of $2 \%$ occur at $50 \mathrm{~km}$ and at $27.5 \mathrm{~km}$. The probability or the confidence interval (CI in $\%)$ that the $11-\mathrm{yr}$ term is present in the data is calculated as in Remsberg et al. (2001). CI values for the terms in Fig. 6 that exceed $90 \%$ are shaded and extend over most of the latitude/altitude domain, except at $55^{\circ} \mathrm{S}$ and at a small region near the tropical stratopause. Qualitatively, the SAGE II response profiles in Fig. 6 at southern middle latitudes agree 


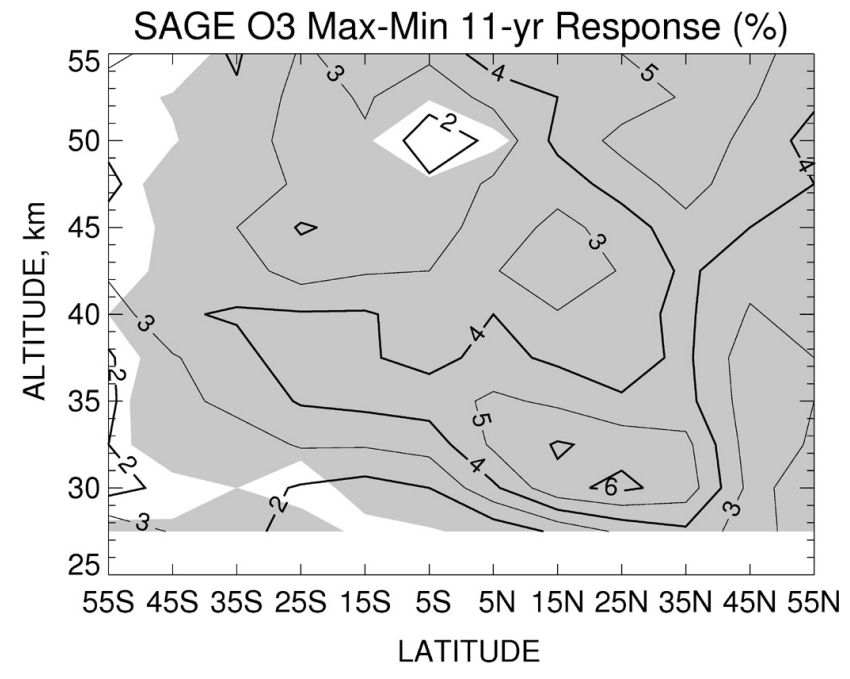

Fig. 6. Contour plot of the maximum minus minimum, 11-yr response (in percent) for the SAGE II ozone data of September 1991 through August 2005. Contour interval is $1.0 \%$. Shading denotes where $\mathrm{CI}>90 \%$ for the responses.

with those reported for 1979 to 2005 from Randel and Wu (2007, their Figure 12a), for 1984 to 2003 from Soukharev and Hood (2006, their Figure 6), and for 1984 to 2000 from Lee and Smith (2003, their Fig. 2b); at tropical latitudes and in the Northern Hemisphere the present findings do not agree with theirs, as well. In particular, there is a clear, SC-like response maximum near $35 \mathrm{~km}$ in Fig. 6 at the tropical latitudes, unlike the response profiles from the foregoing published analyses.

Figure 7 shows the distribution of the phases of the 11-yr terms from SAGE II. Solar maximum uv-flux values occur broadly from early 1989 to early 1992 and in 2001/2002, based on the time series of the solar flux in Soukharev and Hood (2006). January 1991 and 2002 are the estimated times of maximum solar uv-flux for the SAGE II data record of this study. Phase values in Fig. 7 are given with respect to 1991 and 2002 and are shown with a contour interval of 1.0 year. Regions shaded gray are where the phases of the 11-yr terms are within \pm 1.0 year of those dates and are defined here as being in-phase with solar flux maximum. At the higher latitudes of the middle stratosphere the 11-yr terms have their maxima occurring just more than 1 year prior to January $1991 / 2002$, and it may be that there are decadal-scale, dynamical forcings confounding the effects of the SC forcing in those regions during the 14-yr period. Still, the diagnosed, 11-yr terms are clearly in-phase with the SC over most of the latitude/altitude domain. Substitution of a solar uv-flux proxy term for the 11-yr terms of the MLR models of SAGE II ought to lead to very similar, max minus min ozone values and phases.

Several aspects of the 11-yr responses in Fig. 6 disagree with that expected from a direct, solar-uv forcing. First,

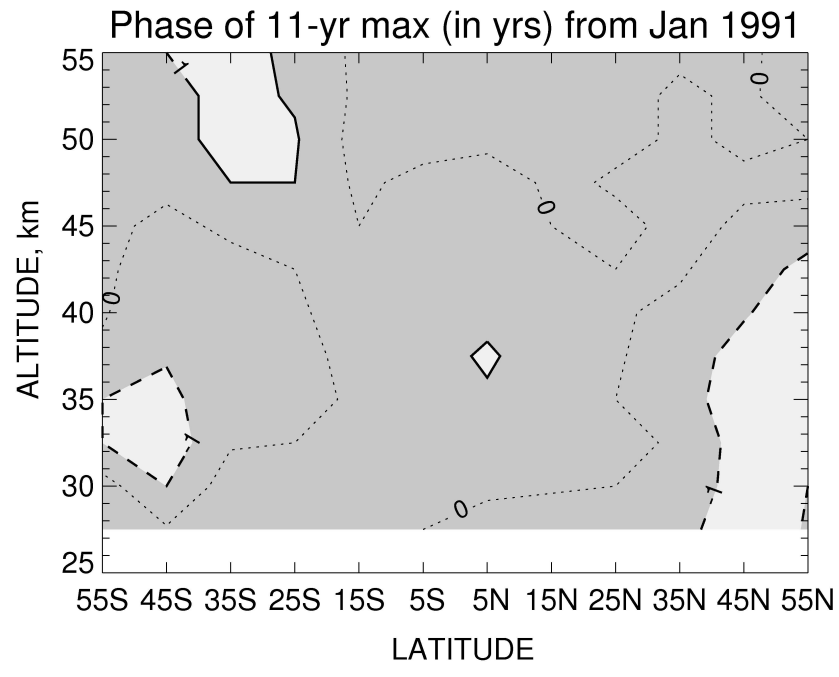

Fig. 7. Contour plot of the phase variations (in years from January 1991 or 2002) of the 11-yr response terms of Figure 6. Contour interval is 1 year. The phase domain of \pm 1 year is shaded and is considered as in-phase with the solar uv-flux maximum.

there is a maximum response of order $5 \%$ in the subtropics of the Northern Hemisphere that is localized between 27.5 and $35 \mathrm{~km}$. No similar feature is present in the Southern Hemisphere. Earlier, it was noted that the MLR model is underestimating the observed ozone in 1991/1992 at $25^{\circ} \mathrm{N}$ and $27.5 \mathrm{~km}$ (Fig. 5). As Lee and Smith (2003) pointed out, it is very likely that there are confounding effects for an analyzed solar cycle term at this location due to ozone forcings from the Pinatubo eruption that occurred near the time of the 1991 solar maximum. For example, radiative cooling at the top of the volcanic aerosol layer increases the slow mean ascent of the tropical stratosphere. Air with lower values of $\mathrm{NO}_{\mathrm{y}}$ would be transported to higher altitudes as a result, and its associated lower $\mathrm{NO}_{x}$ would lead to slightly enhanced values of ozone at chemical equilibrium. In support of that prospect, Hood and Soukharev (2006) reported finding 10\% reductions in $\mathrm{HALOE} \mathrm{NO}_{x}$ at $10 \mathrm{hPa}(\sim 30 \mathrm{~km})$ and at the low latitudes in early 1992. Whatever are the true mechanism(s), the evidence from Figure 6 is that those effects were not communicated to the southern subtropics.

Another hemispheric asymmetry in the results of Figure 6 are its max minus min values at and above $45 \mathrm{~km}$ that are larger at northern than southern middle latitudes (or 5\% versus $3.5 \%$ ). A similar asymmetrical pattern for the decadalscale response from the HALOE ozone will be shown for the subtropics near $2 \mathrm{hPa}$ in Sect. 4 and taken from Remsberg (2008). Figure 7 indicates that the response at the northern middle latitudes is also not quite in-phase with solar maximum. It is postulated that these patterns are due to hemispheric asymmetries in the dynamical forcings during Northern Hemisphere winter, perhaps related to the Northern Hemisphere annular mode (or NAM) (e.g., Kiesewetter et al., 


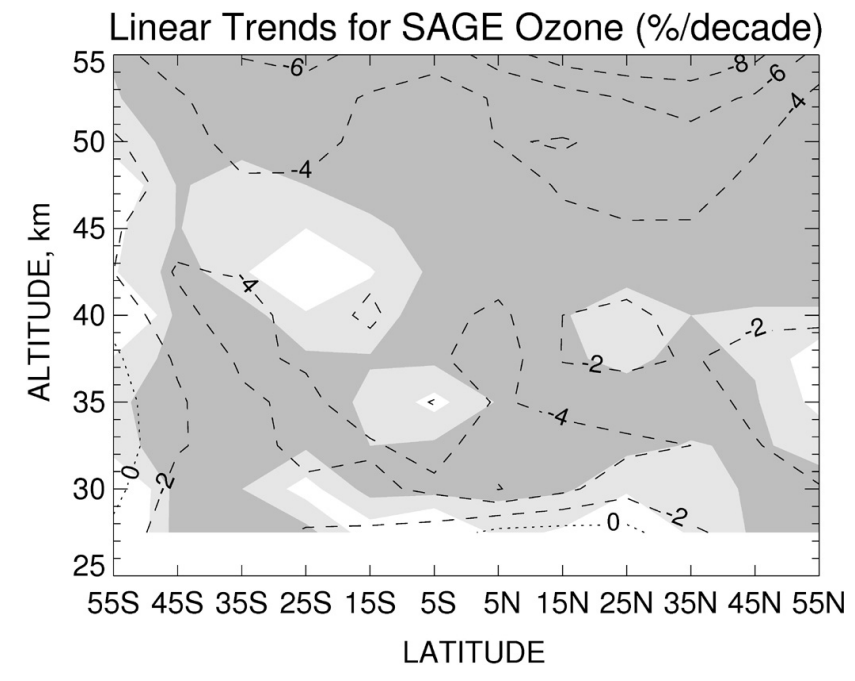

Fig. 8. Contour plot of the linear trend terms (in percent per decade) from the MLR models for the SAGE II ozone data of 1991 to 2005. Contour interval is $2 \%$ /decade. Dashed contours denote negative trends, and the dotted contour is where the trends are zero. Darker shading denotes where $\mathrm{CI}>90 \%$ for the trends; lighter shading has $70 \%<\mathrm{CI}<90 \%$.

2010). During wintertime there is a significant meridional gradient in the zonal mean ozone distribution at middle latitudes of the upper stratosphere. If the polar vortex is stable through the winter, that gradient is maintained. However, the occurrence of a midwinter stratospheric warming will cause a net transport of ozone to higher latitudes, where the lifetime for ozone destruction is long. Midwinter warming events occurred in the early 1990s and again in the early years of the 2000 decade, or for those years near solar flux maximum (Manney et al., 2005). Conversely, no midwinter warming events occurred near solar minimum or during the middle part of the 1990s (Pawson and Naujokat, 1999). Thus, these variations in the occurrence of the warming events may have led to an enhancement of the diagnosed solar cycle response at the northern middle latitudes. Unfortunately, there are too few SAGE II samples at the higher latitudes for conducting time series analyses for a specific month or season of the year or for resolving the effects of a winter warming. Similar midwinter warming events seldom occur in the Southern Hemisphere and, therefore, are unlikely to have affected its decadal scale ozone responses.

Figure 8 is a contour plot of the linear trend terms (in $\% /$ decade) from the MLR analyses of the SAGE II ozone, and they are negative nearly everywhere. The CI values greater than $90 \%$ in Fig. 8 are shaded and mostly cover the trends that are more negative than $-3 \% /$ decade. The relatively large, negative trends at 30 to $35 \mathrm{~km}$ in the subtropics of the Northern Hemisphere seem to be related to anomalous effects in 1991/1992, based on the analyses in the following subsection. Trends in the upper stratosphere $(45 \mathrm{~km})$ are somewhat less negative and nearly constant with latitude (about $-3 \% / d e c a d e)$. Randel and Wu (2007, their Figure 8a) and $\mathrm{Li}$ et al. (2002) reported that the effect of a gas phase, chlorine-induced ozone loss yields negative ozone trends that are largest between 35 and $45 \mathrm{~km}$ and at the higher latitudes. The trends in Fig. 8 for 1991-2005 do not have that character.

\subsection{September 1992 through August 2005}

The MLR results of Fig. 5 indicated that the 11-yr and trend terms in Figs. 6 and 8 at the northern subtropical latitudes may be affected by the forcings from the Pinatubo layer in the middle stratosphere. In fact, the underestimate of the SAGE II ozone by the MLR model in late 1991 and early 1992 is an excellent example of "end point anomaly" effects for time series analyses. It seems prudent to avoid the late 1991 and early 1992 period in a repeat of our MLR analyses. The changing effects of the reactive chlorine for the upper stratospheric ozone should also be lessened. Thus, in this subsection the distributions of the amplitudes and phases of the 11-yr terms and of the linear trend terms are analyzed and shown for the period September 1992 through August 2005.

Figure 9 shows the max minus min responses for the 11-yr terms from that $13-y r$ time series. Now, the peak responses at $35 \mathrm{~km}$ are only of order $3 \%$, and they are more symmetric with latitude across the two hemispheres than in Fig. 6. Minimum responses of order $1 \%$ occur in the tropics at $27.5 \mathrm{~km}$ and at about $45 \mathrm{~km}$. Regions of the domain where the CI values exceed $90 \%$ are shaded, and one can see that the significance of the terms is less and not as extensive as in Fig. 6. On the other hand, the maximum response of about $5 \%$ near $35^{\circ} \mathrm{N}$ and $50 \mathrm{~km}$ is nearly unchanged from before. It is also noted that the results of the model simulations that include only solar and QBO forcings (see Lee and Smith, 2003; their Fig. 14a) show an ozone response pattern in the upper stratosphere that is quite similar to that of Fig. 9.

Figure 10 shows the distribution of the phases of the 11-yr terms of Fig. 9. Phases are similar to the ones of Fig. 7, except for those small regions where the max minus min values are also small $(<1 \%)$ and not significant. The ozone response at $5^{\circ} \mathrm{N}$ near 35 to $40 \mathrm{~km}$ in Fig. 10 occurs about 1 to 1.5 years after January 1991, or very near to the time of the absolute maximum for the solar uv-flux for that cycle. As before, Figure 10 shows that there is disagreement in the phase with that of the SC uv-flux poleward of $35^{\circ} \mathrm{N}$ and from about $27.5 \mathrm{~km}$ to $35 \mathrm{~km}$, presumably because of confounding contributions of similar amplitude from dynamical forcings.

The linear trend values are shown in Fig. 11. They are not as negative in the stratosphere as those of Figure 8, and only the trends of $-3 \% /$ decade or greater are significant at $90 \%$ CI. Trends are of order zero across all latitudes from about 40 to $45 \mathrm{~km}$, similar to those from the HALOE analyses of Remsberg (2008). Again, this finding is noteworthy because that altitude region is where the chemical changes for ozone due to any trends in the reactive chlorine would ordinarily 


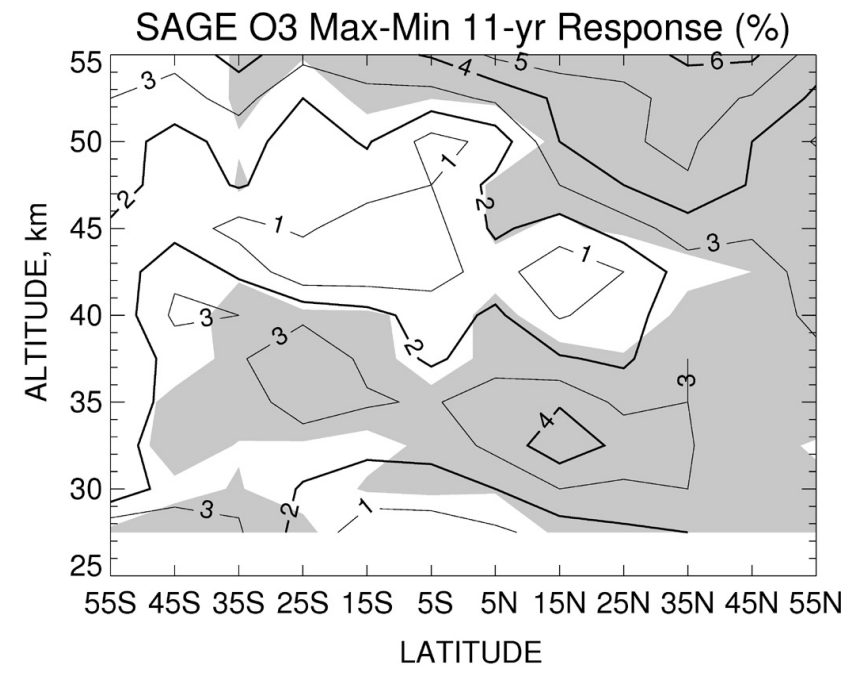

Fig. 9. As in Fig. 6, but the max minus min variations are from the SAGE II data from September 1992 through August 2005.

be the largest. Stratospheric chlorine was increasing at a rate of about 3\%/yr from September 1991 to 1996 (WMO, 2007, Figs. 1-12), so truncating the SAGE II time series by one year can explain the noticeable differences for both the SClike and linear ozone response terms. In fact, Figure 8 shows that the trend at that altitude was $-3 \% /$ decade for the period of 1991-2005, while it is near zero in Fig. 11 for 1992-2005. At the same time the 11-yr responses were changed by only $1 \%$ (c.f., Fig. 6 and Figure 9), although those differences are not significant at $90 \%$ CI. Even though the effects of the chlorine may have been somewhat non-linear from 19922005, the above results indicate that a linear approximation to them does not alter the analyzed 11-year responses by much. Ozone trends are also now closer to zero and less significant just above the top of the Pinatubo aerosol layer, as a result of deleting the 1991-1992 data.

\section{Comparisons between SAGE, HALOE, and the Brasseur model}

The results of the analyses of the HALOE ozone time series are discussed in this section. Note that those analyses are taken from Remsberg (2008) but have also been extended upward to the $0.2-\mathrm{hPa}$ level or near $60 \mathrm{~km}$ in the present study, in order to make a better judgment about differences between the HALOE and SAGE II responses in the lower mesosphere. Figure 12 is the 11-yr ozone responses from HALOE for comparison with the foregoing ones from SAGE II (i.e., Figs. 6 and 9); the responses from HALOE are smaller and not as significant in the upper stratosphere. Upon masking the responses from both data sets above about $50 \mathrm{~km}$ (or the 1-hPa level), the patterns in Figs. 9 and 12 appear quite similar. Figure 13 shows the associated distribution of the phases

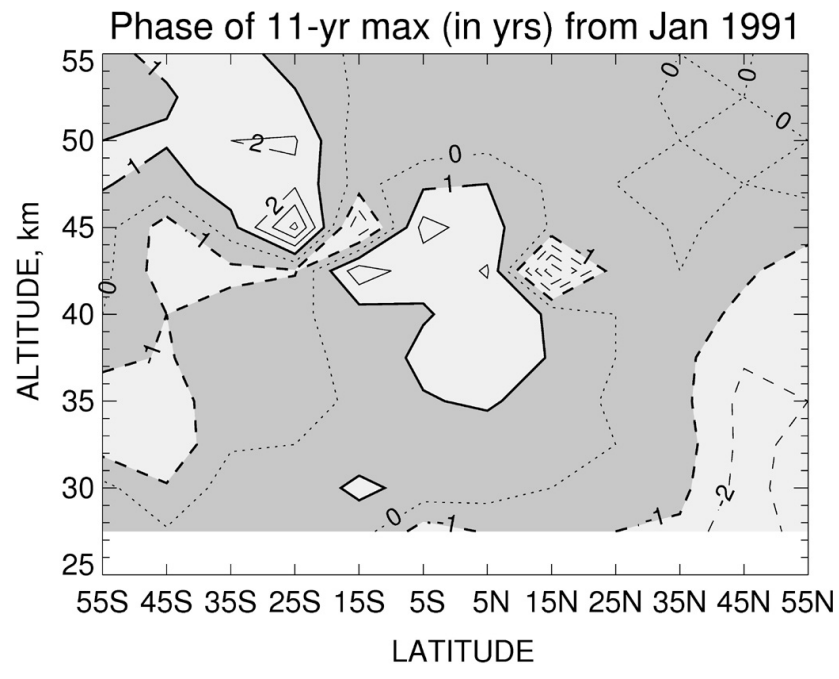

Fig. 10. As in Fig. 7, but the phases are from the SAGE II data from September 1992 through August 2005.

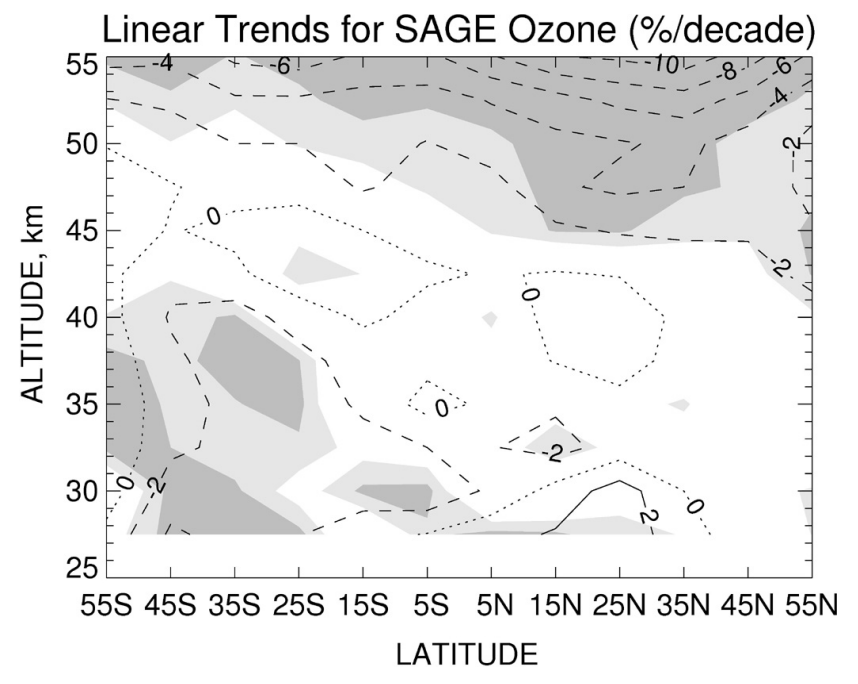

Fig. 11. As in Fig. 8, but the trends are from the SAGE II data from September 1992 through August 2005. The solid contour denotes a positive trend.

of the 11-yr terms from HALOE, and they are mostly inphase with solar flux maximum. The major exceptions are near the stratopause and below the 10-hPa level in the tropics, where the 11-yr responses from HALOE are not significant. In general, the 11-yr responses from SAGE II are more closely in-phase with the solar uv-flux.

Figure 14 shows the distribution of the linear trends from the HALOE ozone, and there are some noticeable differences from those of SAGE II (Figures 8 and 11). For instance, the HALOE trends are more negative than those of SAGE II just below $30 \mathrm{~km}$ (or the 10-hPa level), but less negative in the upper stratosphere. This profile difference for the trends is consistent with the fact that there has been a cooling in the 


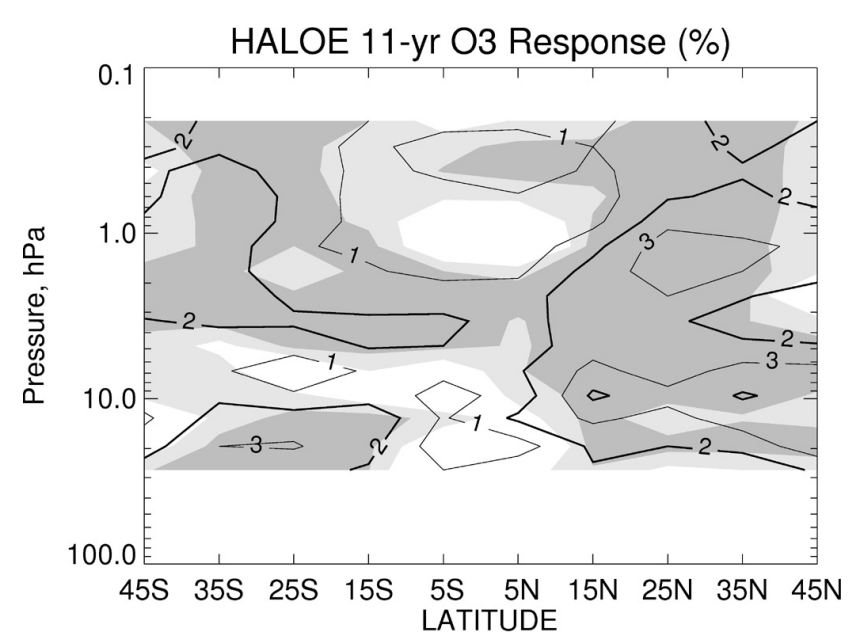

Fig. 12. As in Fig. 6, but for the HALOE max minus min, 11yr responses in ozone. Darker shading denotes where CI $>90 \%$; lighter shading denotes $70 \%<\mathrm{CI}<90 \%$.

time series of temperature versus altitude in the middle atmosphere, primarily due to the increasing $\mathrm{CO}_{2}$ (Steinbrecht et al., 2009; Remsberg, 2009). Still, the trend differences for the upper stratosphere are greater by a factor of two from the modeled differences of Rosenfield et al. (2005, their Figure 6). That disagreement may be a consequence of differences for the trends of the temperature data used to process the respective ozone datasets or due to unmodeled interactions between ozone and temperature. Note that the trends from the HALOE data in Fig. 14 are essentially zero at low to middle latitudes near the stratopause and through the lower mesosphere, which is expected if there are no changes from the chemical production or loss terms for ozone at those upper altitudes. In contrast, the trends in that region from SAGE II are increasingly negative with altitude in Figs. 8 and 11.

The separate, 11-yr ozone response profiles from the SAGE II data are now averaged across the 20-degree wide, latitude zones of $15^{\circ} \mathrm{S}, 5^{\circ} \mathrm{S}, 5^{\circ} \mathrm{N}$, and $15^{\circ} \mathrm{N}$ or effectively from $25^{\circ} \mathrm{S}$ to $25^{\circ} \mathrm{N}$. Those results are plotted in Fig. 15 for both the 1991-2005 and the 1992-2005 periods. The results from HALOE were averaged in the same way, and they are also included in Fig. 15 along with the Brasseur model profile from Fig. 1. The reader is reminded that both the HALOE and the Brasseur model results are ozone response profiles in pressure coordinates. Both 11-yr response profiles from SAGE II have a similar shape to those of HALOE and of the model throughout most of the stratosphere, but are somewhat larger in magnitude. The character and vertical location of the peak response for the SAGE II ozone also agrees with those from HALOE and the model, unlike the SAGE results of Randel and Wu (2007), as reported in WMO (2007) and shown in Fig. 1. It is presumed that much of differences is due to uncertainties for the registration of the SAGE I profiles of 1979-1981 and for the accounting of the much larger ef-

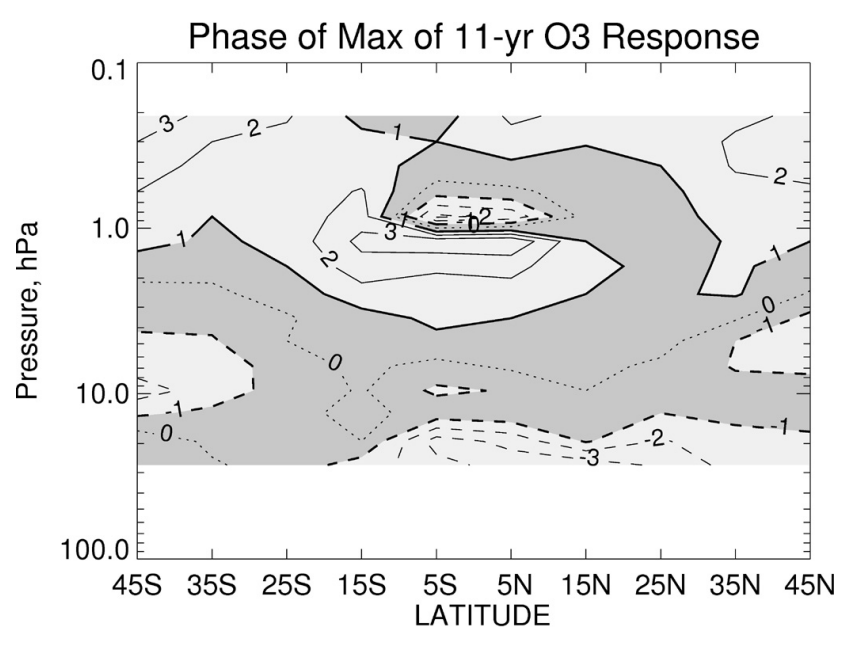

Fig. 13. As in Fig. 7, but for the phase of the 11-yr terms from the HALOE ozone.

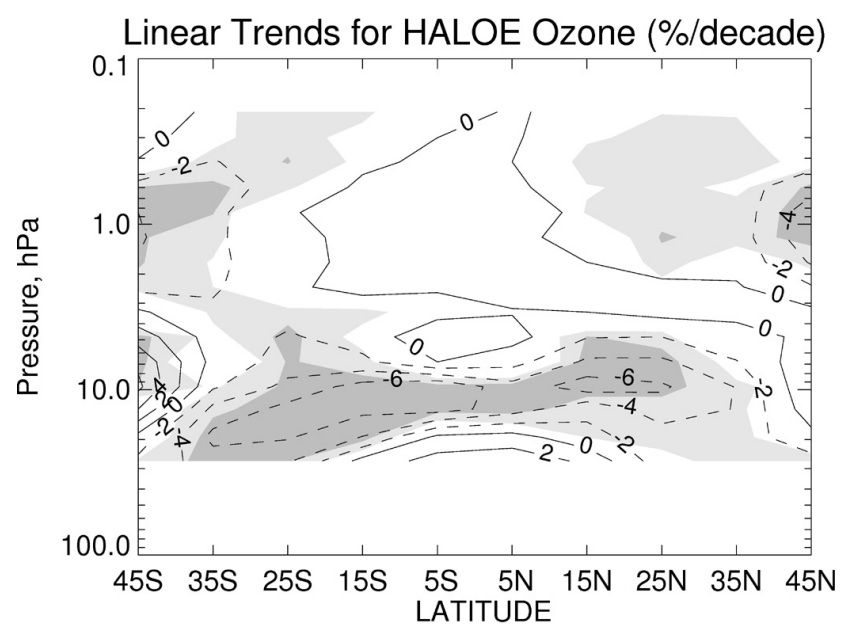

Fig. 14. As in Fig. 8, but for the linear trend terms from the HALOE ozone. Regions of darker shading denote $\mathrm{CI}>90 \%$; regions of lighter shading have $70 \%<\mathrm{CI}<90 \%$.

fects of the changing chlorine of the 1980s. As noted earlier, Lee and Smith (2003) were able to obtain a pattern of ozone responses that agreed with their model simulations once they removed the SAGE II data that were affected by the Pinatubo aerosol layer.

Near the stratopause and into the lower mesosphere the responses from SAGE II disagree with those from HALOE and the model, most likely a result of the associated differences for the ozone trends from the two data sets. To test that assumption, Fig. 15 also contains an 11-yr response profile (dotted) from a second set of analyses of the SAGE II data of 1991 to 2005, but without the inclusion of the linear trend term in the regression model. The comparison of the SAGE II 11-yr profiles, with and without the trend term, is a measure of the sensitivity of the magnitudes of their responses 
11-yr O3 Response: SAGE, HALOE, Model

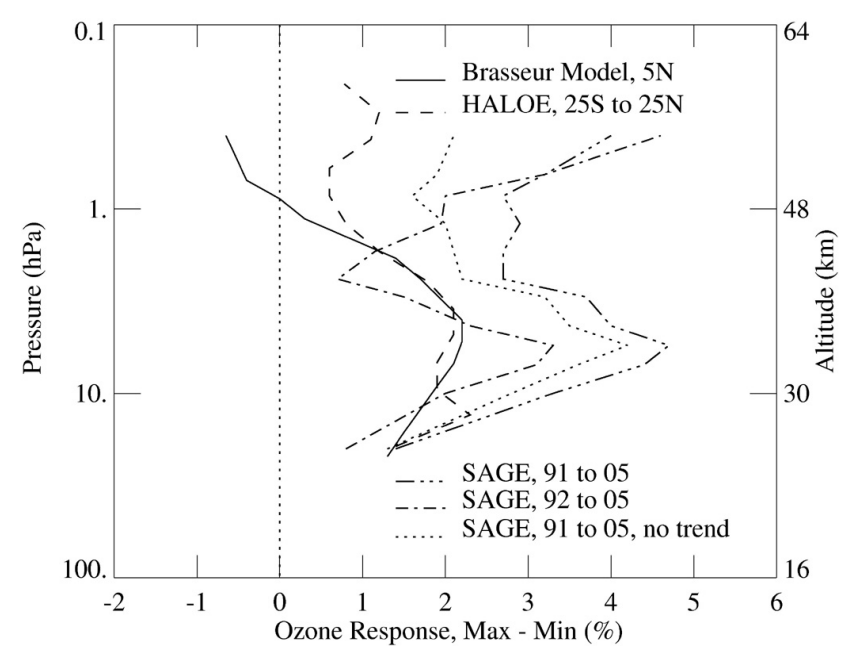

Fig. 15. Profiles of the 11-yr, max minus min ozone responses (in percent) from the Brasseur model (solid), HALOE data (dashed), and the SAGE II data from 91 to 05 (dash-dot-dot-dot), from 92 to 05 (dash-dot), and again from 91 to 05 but with no trend term (dotted).

from the MLR models in the presence of the trend. Those differences are only of the order of $0.5 \%$ for the peak responses at altitudes of 30 to $40 \mathrm{~km}$. As indicated by the dark shadings in Figs. 6 (SAGE II) and 12 (HALOE), the 11-yr responses (and response differences) of less than $2 \%$ are not significant at $90 \%$ CI. One can also see that the SAGE II response profile (dotted) obtained by excluding the trends is yielding a profile shape very similar to that of HALOE at the upper altitudes, though still of larger magnitude. The net result is that the exclusion of the relatively large negative trends from the SAGE II MLR analysis is responsible for a corresponding reduction of its positive, 11-yr responses in the lower mesosphere. Therefore, it is tentatively concluded that there was a spurious trend in the SAGE II ozone at these altitudes, at least for part of the 1991-2005 period. It is more likely that the true ozone trends were less negative to nearly zero and that the max minus min ozone responses ought to be no larger than $2 \%$, as indicated by the dotted curve in Fig. 15.

SAGE II ozone transmission profiles of the lower mesosphere are subject to a large correction from the effects of atmospheric Rayleigh scattering (Wang et al., 1992). The associated neutral density profiles for the SAGE II algorithm (L. Thomason, personal communication, 2010) are obtained from operational temperature data up to about $50 \mathrm{~km}$ with a tie-in to the GRAM-90/95 reference model of Justus et al. (1991) for the mesosphere. Temperatures for the GRAM model were obtained from meteorological rocket profiles and from the Selective Chopper Radiometer (SCR) and Pressure Modulation Radiometer (PMR) climatologies of the 1970s. Since that time there has been a rather steady cooling of the mesosphere and a contraction (or lowering) of atmospheric density at a constant altitude (e.g., Remsberg, 2009). The corresponding Rayleigh correction should have been getting smaller with time. Nevertheless, there is no indication of any bias in the SAGE II ozone trends at $50 \mathrm{~km}$ and below from 1984-1997, a period when the ozone loss due to chlorine was about $5 \% /$ decade at $40 \mathrm{~km}$ ( $\mathrm{Li}$ et al., 2002). According to the results in Fig. 11, the SAGE II ozone trend at $40 \mathrm{~km}$ was more nearly zero for $1992-2005$, while at $55 \mathrm{~km}$ it was still decreasing by $6 \% /$ decade. Midway through that period NOAA replaced the Stratospheric Sounding Unit (SSU) with the Advanced Microwave Sounding Unit (AMSU-A) as its operational temperature profiler for the middle and upper stratosphere. The NOAA Climate Prediction Center provided its operational temperatures to the UARS (HALOE) and SAGE Projects, switching from SSU to AMSU-A profiles in 2001. The top SSU channel covers a rather broad atmospheric region and its weighting function is centered at about $1.5 \mathrm{hPa}$, while that of AMSU-A is narrower and centered at about $2.5 \mathrm{hPa}$. Several recent, middle atmosphere temperature validation studies have indicated that the operational temperatures are too warm above $45 \mathrm{~km}$ and by as much as 5 to $10 \mathrm{~K}$ in the lower mesosphere at the low latitudes (Ridolfi et al., 2007; Gille et al., 2008; Masiello et al., 2010). It is suspected that there is also a warm bias for the SAGE II temperatures, especially after mid-2001. A warm bias translates to overestimated pressures, molecular number densities, and Rayleigh correction; the derived ozone number densities would be underestimated by at least several percent (Wang et al., 1996). A consequence may be the larger than expected, negative SAGE II ozone trends of the lower mesosphere in Figs. 8, 11, and 15.

\section{Summary}

Time series analyses of SAGE II ozone data were undertaken to determine whether their decadal-scale effects are consistent with those predicted for the 11-yr, solar uv-flux forcing. The period of 1991-2005 was chosen because it is the same as that for the HALOE analyses of Remsberg (2008) and because atmospheric chlorine and its effects on ozone were not changing by much at that time. The SAGE II analyses were performed between $55^{\circ} \mathrm{S}$ and $55^{\circ} \mathrm{N}$ and from $27.5 \mathrm{~km}$ to $55.0 \mathrm{~km}$, using an MLR model that includes seasonal, interannual, 11-yr, and linear trend terms. However, none of the terms was based on external, proxy data time series. Still, the simple, 11-yr sinusoid term was found to be essentially in-phase with that of solar proxies and had max minus min variations of up to $4 \%$. The SAGE II response profiles had peak values between 30 and $40 \mathrm{~km}$ and agreed with those from the HALOE data and most models, after allowing for the small periodic variations of pressure versus altitude. The associated, linear trend terms from the SAGE II analyses were slightly negative ( -2 to $-4 \% /$ decade) for this 
14-yr time span. There was also a negative, decadal-scale response in the SAGE II ozone that grew larger from just below the stratopause and into the lower mesosphere. At the low latitudes that secondary 11-yr response may be mainly the result of an interaction with a spurious, linear trend.

The results of this study indicate that the solar occultation technique has the signal sensitivity and vertical resolution for recording the response of stratospheric ozone to changes of the uv-flux forcing over the 11-yr solar cycle. For the long-term monitoring of ozone it is recommended that SAGE-type instruments be operated from satellites in moderately inclined orbits and hopefully with some overlap between successive satellites. It should be clear that one can only resolve the various long-term responses from their measurements, if all other decadal-scale forcings and trends are either insignificant or accounted for in the regression model for the analysis of the observed ozone time series. As a caution, recent model studies of Smith and Matthes (2008) and $\mathrm{Lu}$ et al. (2009) show that at least two to three decades of satellite data may be needed, in order to separate the longterm effects of the solar cycle forcing from those of decadalscale dynamical forcings. The results of the present analyses indicate that it is more likely that any such decadal-scale, dynamical influences will occur in the northern than in the Southern Hemisphere.

Acknowledgements. The SAGE II Version 6.2 data were generated by personnel of the Radiation and Aerosols Branch of NASA Langley. We thank Randy Moore (SSAI) for his assistance with the download of the data and for providing software for reading the archived data. This research was supported by funds from Jack Kaye of NASA Headquarters and administered by Joe Zawodny within his Solar Occultation Satellite Science Team (SOSST) study activity. Funds were also provided from a proposal of the NASA MAP Program administered by David Considine. EER completed this manuscript while serving as a Distinguished Research Associate at NASA Langley under the sponsorship of Malcolm Ko.

Edited by: A. Baumgaertner

\section{References}

Brasseur, G.: The response of the middle atmosphere to longterm and short-term solar variability: a two-dimensional model, J. Geophys. Res., 98, 23079-23090, doi:10.1029/93JD02406, 1993.

Dunkerton, T. J.: Quasi-biennial and subbiennial variations of stratospheric trace constituents derived from HALOE observations, J. Atmos. Sci., 58, 7-25, 2001.

Fioletev, V. E.: Estimating the 27-day and 11-year solar cycle variations in tropical upper stratosphere ozone, J. Geophys. Res., 114, D02302, doi:10.1029/2008JD010499, 2009.

Frame, T. H. A. and Gray, L. J.: The 11-yr solar cycle in ERA-40 data: an update to 2008, J. Climate, 23, 2213-2222, doi:10.1175/2009JCLI3150.1, 2010.

Gille, J., Barnett, J., Arter, P., Barker, M., Bernath, P., Boone, C., Cavanaugh, C., Chow, J., Coffey, M., Craft, J., Craig, C., Di- als, M., Dean, V., Eden, T., Edwards, D. P., Francis, G., Halvorson, C., Harvey, L., Hepplewhite, C., Khosravi, R., Kinnison, D., Krinsky, C., Lambert, A., Lee, H., Lyjak, L., Loh, J., Mankin, W., Massie, S., McInerney, J., Moorhouse, J., Nardi, B., Packman, D., Randall, C., Reburn, J., Rudolf, W., Schwartz, M., Serafin, J., Stone, K., Torpy, B., Walker, K., Waterfall, A., Watkins, R., Whitney, J., Woodard, D., and Young, G.: High Resolution Dynamics Limb Sounder: Experiment overview, recovery, and validation of initial temperature data, J. Geophys. Res., 113, D16S43, doi:10.1029/2007JD008824, 2008.

Gordley, L., Thompson, E., McHugh, M., Remsberg, E., Russell III, J., and Magill, B.: Accuracy of atmospheric trends inferred from the Halogen Occultation Experiment data, J. Appl. Remote Sens., 3, 033526, doi:10.1117/1.3131722, 2009.

Hassler, B., Bodeker, G. E., and Dameris, M.: Technical Note: A new global database of race gases and aerosols from multiple sources of high vertical resolution measurements, Atmos. Chem. Phys., 8, 5403-5421, doi:10.5194/acp-8-5403-2008, 2008.

Hood, L. L. and Soukharev, B. E.: Solar induced variations of odd nitrogen: multiple regression analysis of UARS HALOE data, Geophys. Res. Lett., 33, L22805, doi:10.1029/2006GL028122, 2006.

Justus, C. G., Alyea, F. N., Cunnold, D. M., Jeffries III, W. R., and Johnson, D. L.: The NASA/MSFC Global Reference Atmospheric Model - 1990 Version (GRAM-90), Part I: Technical/Users Manual, NASA Tech. Memo. 4268, 1991.

Kiesewetter, G., Sinnhuber, B.-M., Vountas, M., Weber, M., and Burrows, J. P.: A long-term stratospheric ozone data set from assimilation of satellite observations: highlatitude ozone anomalies, J. Geophys. Res., 115, D10307, doi:10.1029/2009JD013362, 2010.

Lee, H. and Smith, A. K.: Simulation of the combined effects of solar cycle, quasi-biennial oscillation, and volcanic forcing on stratospheric ozone changes in recent decades, J. Geophys. Res., 108, 4049, doi:10.1029/2001JD001503, 2003.

Li, J., Cunnold, D. M., Wang, H.-J., Yang, E.-S., and Newchurch, M. J.: A discussion of upper stratospheric ozone asymmetries and SAGE trends, J. Geophys. Res., 107(D23), 4705, doi:10.1029/2001JD001398, 2002.

Lu, H., Gray, L. J., Baldwin, M. P., and Jarvis, M. J.: Life cycle of the QBO-modulated 11-year solar cycle signals in the northern hemispheric winter, Q. J. Roy. Meteorol. Soc., 135(641), 10301043, doi:10.1002/qj.419, 2009.

Manney, G. L., Krüger, K., Sabutis, J. L., Sena, S. A., and Pawson, S.: The remarkable 2003-2004 winter and other recent warm winters in the Arctic stratosphere since the late 1990s, J. Geophys. Res., 110, D04107, doi:10.10292004JD005367, 2005.

Masiello, G., Matricardi, M., and Serio, C.: The use of IASI data to identify systematic errors in the ECMWF temperature analysis in the upper stratosphere, Atmos. Chem. Phys. Discuss., 10, 22725 22764, doi:10.5194/acpd-10-22725-2010, 2010.

McCormick, M. P., Zawodny, J. M., Veiga, R. E., Larsen, J. C., and Wang, P. H.: An overview of SAGE I and II ozone measurements, Planet. Space Sci., 37, 1567-1586, 1989.

Pawson, S. and Naujokat, B.: The cold winters of the middle 1990s in the northern lower stratosphere, J. Geophys. Res., 104, 1420914222, doi:10.1029/1999JD900211, 1999.

Randel, W. J. and Wu, F.: A stratospheric ozone profile data set for 1979-2005: Variability, trends, and comparisons 
with column ozone data, J. Geophys. Res., 112, D06313, doi:10.1029/2006JD007339, 2007.

Remsberg, E.: Trends and solar cycle effects in temperature versus altitude from the Halogen Occultation Experiment for the mesosphere and upper stratosphere, J. Geophys. Res., 114, D12303, doi:10.1029/2009JD011897, 2009.

Remsberg, E. E.: On the response of Halogen Occultation Experiment (HALOE) stratospheric ozone and temperature to the 11-yr solar cycle forcing, J. Geophys. Res, 113, D22304, doi:10.1029/2008JD010189, 2008.

Remsberg, E. E. and Deaver, L. E.: Interannual, solar cycle, and trend terms in middle atmospheric temperature time series from HALOE, J. Geophys. Res., 110, D06106, doi:10.1029/2004JD004905, 2005.

Remsberg, E. E., Bhatt, P. P., and Deaver, L. E.: Ozone changes in the lower stratosphere from the Halogen Occultation Experiment for 1991 through 1999, J. Geophys. Res., 106(D2), 1639-1653, 2001.

Ridolfi, M., Blum, U., Carli, B., et al.: Geophysical validation of temperature retrieved by the ESA processor from MIPAS/ENVISAT atmospheric limb-emission measurements, Atmos. Chem. Phys., 7, 4459-4487, doi:10.5194/acp-7-4459-2007, 2007.

Rosenfield, J. E., Frith, S. M., and Stolarski, R. S.: Version 8 SBUV ozone profile trends compared with trends from a zonally averaged chemical model, J. Geophys. Res., 110, D12302, doi:10.1029/2004JD005466, 2005.

Shine, K. P., Barnett, J. J., and Randel, W. J.: Temperature trends derived from Stratospheric Sounding Unit radiances: The effect of increasing $\mathrm{CO}_{2}$ on the weighting function, Geophys. Res. Lett., 35, L02710, doi:10.1029/2007GL032218, 2008.

Smith, A. K. and Matthes, K., Decadal-scale periodicities in the stratosphere associated with the solar cycle and the QBO, J. Geophys. Res., 113, D05311, doi:10.1029/2007JD009051, 2008.

Soukharev, B. E. and Hood, L. L.: Solar cycle variation of stratospheric ozone: Multiple regression analysis of long-term satellite data sets and comparisons with models, J. Geophys. Res., 111, D20314, doi:10.1029/2006JD007107, 2006.
SPARC/IOC/GAW: Assessment of Trends in the Vertical Distribution of Ozone, World Climate Research Programme, Report No. 1, WMO Ozone Research and Monitoring Project, Report No. 43, 1998.

SPARC CCMVal, SPARC CCMVal Report on the Evaluation of Chemistry-Climate Models, Eyring, V., Shepherd, T. D., and Waugh, D. W., (Eds.), SPARC Report No. 5, WCRPX, WMO/TD-No. X, available online at: http://www.atmosp. physics.utoronto.ca/SPARC, 2010.

Steinbrecht, W., Claude, H., Schoenenborn, F., McDermid, I. S., LeBlanc, T., Godin-Beekmann, S., Keckhut, P., Hauchecorne, A., Van Gijsel, J. A. E., Swart, D. P. J., Bodeker, G., Parrish, A., Boyd, I., Kämpfer, N., Hocke, K., Stolarski, R. S., Frith, S. M., Thomason, L. W., Remsberg, E. E., Von Savigny, C., Rozanov, A., and Burrows, J. P.: Ozone and temperature trends in the upper stratosphere at five stations of the Network for the Detection of Atmospheric Composition Change, Int. J. Remote Sens., 30, 3875-3886, 2009.

Tiao, G. C., Reinsel, G. C., Xu, D., Pedrick, J. H., Zhu, X., Miller, J. A., DeLuisi, J. J., Mateer, C. L., and Wuebbles, D. J.: Effects of autocorrelation and temporal sampling schemes on estimates of trend and spatial correlation, J. Geophys. Res., 95, 20507-20517, doi:10.1029/JD095iD12p20507, 1990.

Wang, H. J., Cunnold, D. M., and Bao, X.: A critical analysis of Stratospheric Aerosol and Gas Experiment ozone trends, J. Geophys. Res., 101, 12495-12514, 1996.

Wang, P.-H., McCormick, M. P., Chu, W. P., Lenoble, J., Nagatani, R. M., Chanin, M. L., Barnes, R. A., Schmidlin, F., and Rowland, M.: SAGE II stratospheric density and temperature retrieval experiment, J. Geophys. Res., 97, 843-864, 1992.

World Meteorological Organization: Scientific assessment of ozone depletion: 2006, Global Ozone Research and Monitoring Project, Report No. 50, 572 pp., Geneva, Switzerland, 2007.

Yang, E. S., Cunnold, D. M., Salawitch, R. J., McCormick, M. P., Russell, J., Zawodny, J. M., Oltmans, S., and Newchurch, M. J.: Attribution of recovery in lower stratospheric ozone, J. Geophys. Res., 111, D17309, doi:10.1029/2005JD006371, 2006. 